\title{
The design and construction of water impounding plugs using sprayed concrete
}

\author{
U. Singh Stratacrete Pty Ltd, Australia
}

P. Abraham Newcrest Mining Ltd, Australia

E. Bellamy Newcrest Mining Ltd, Australia

A. Swart Newcrest Mining Ltd, Australia

\begin{abstract}
Water containment plugs for the management of an uncontrolled inflow of water are common in coal mines but not a usual requirement for hard rock mines. An underground operation beneath an operating open pit requires water plugs to be constructed to isolate the active underground workings from potential uncontrolled inflow of water from the open pit during high rainfall events. The site had previous experience in constructing two concrete plugs using formwork and poured concrete. Construction hazards and leakage around the constructed plug lead the site to explore alternative construction methods which would provide a better seal and expose construction crews to fewer hazards. A method for using sprayed concrete to construct the plugs was developed. This method provides a better seal between the plug and the rock; however, it raises challenges to control the heat generation from the sprayed concrete while maintaining sufficient binder content to allow for spraying and build-up of concrete. The paper discusses the design and construction of these plugs.
\end{abstract}

\section{Introduction}

The Telfer open pit is situated directly above the Telfer underground mine and is being mined through old underground workings. These underground excavations are linked to the current underground workings via an old decline, ventilation shafts and drill holes.

The Telfer region is subjected to periodic cyclones in the wet season which have the potential to deposit high rainfall in very short durations. The pit, which is approximately $1.2 \times 3 \mathrm{~km}$ in area and $350 \mathrm{~m}$ deep, provides a large catchment for collecting the rainfall.

The water is collected in sumps in the pit and in the under-pit water storage which consists of old stopes and workings that have been sealed off by water containment plugs (Figure 1). This water is pumped out using high volume pumps in the pit and the underground pumping system. Thus, the under-pit water storage is not subjected to large heads for extended durations, however, there is potential for a large head for a short duration if a major cyclone event was to deposit significant amounts of rain in the area.

Open pit mining for Stage 3 of the Main Dome pit was expected to compromise the existing water containment plugs, thus triggering the requirement for new plugs. Previous experiences with plug construction on site lead the project team to investigate alternative construction methods which would be safer to construct and provide an improved seal.

This paper discusses the design and construction of these plugs. Although three plugs were constructed, this paper will only discuss the design and construction of the two decline plugs as these are the most typical plug scenarios encountered in mining. 


\section{1 Telfer Mine}

The Telfer Gold Mine owned by Newcrest Mining Limited is located in the Great Sandy Desert some $600 \mathrm{~km}$ east-southeast of Port Hedland.

The Telfer deposit was discovered in 1971 when anomalous gold and copper values were returned from outcrops in what is now known as Main Dome. In late 2000, the operation was put into care and maintenance after producing approximately $6 \mathrm{Moz}$ of gold. A feasibility study for bulk mining was completed in 2002 and this lead to the reestablishment of mining operations.

Telfer is currently producing from the Main Dome pit and the underground operations which consist of a sublevel cave (SLC) and narrow vein long hole open stoping. The SLC was initiated in late 2006 with the SLC extraction levels some $800 \mathrm{~m}$ below the western wall of the open pit.

The open pit is currently mining at rates in the order of $50 \mathrm{Mtpa}$ of ore and waste, while the underground is hoisting in the order of $6 \mathrm{Mtpa}$. The ore sources combine to feed a mill that treats approximately $20 \mathrm{Mtpa}$.

The sublevel cave broke through into the western side of the Main Dome open pit in late 2009. Stage 3 of the pit was successfully mined with the haulage ramp located approximately $60 \mathrm{~m}$ from the breakthrough (Singh et al., 2010; Dixon et al., 2010). The pit is currently mining Stage 4 on the eastern side of the pit.

\section{2 Flood management}

The Telfer underground operations are situated below the Main Dome pit which is mining through old underground workings. The pit and the underground are connected through these old workings, vertical raises, drill holes and the 130 decline (Figure 1). The old workings have been used as an under-pit water containment system and have been an integral part of the Telfer water management plan. The water storage system is designed to capture large rainfall events produced during cyclones in the Pilbara region. The water is then pumped out in a controlled manner by the open pit and underground pumps. The under pit water storage was isolated from the active workings by the 130 water plug and the VR2C water plug (Figure 1).

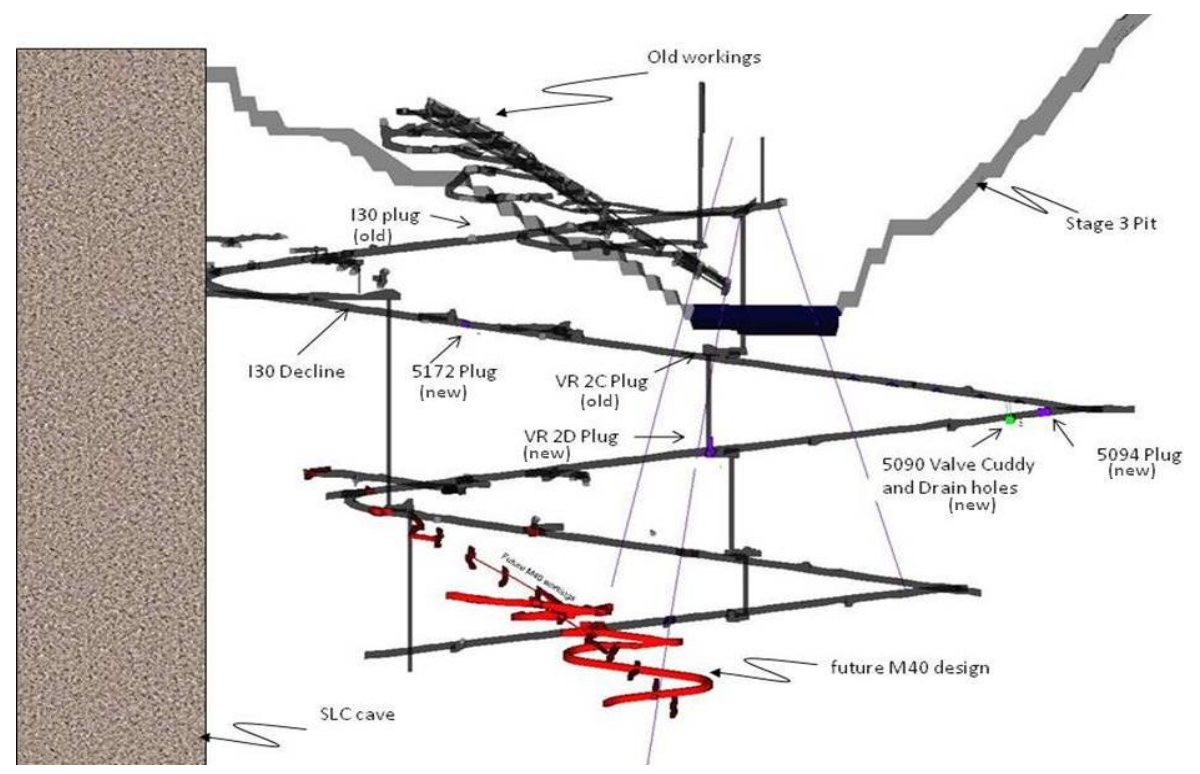

Figure 1 Schematic section through the pit and under-pit workings, showing the positions of the old and new plugs

Mining of the Stage 3 open pit removed much of the under-pit workings used for water storage thus limiting its storage capacity. The Stage 3 pit also mined past the 130 plug thus making it redundant; and compromised the VR2C plug which was decommissioned before the 2010 wet season. New water plugs were required outside the zone of influence of the Stage 3 pit. 


\section{$2 \quad$ Plug scope}

New water containment plugs were required to isolate the underground operations from water collected in the pit catchment, such that the underground mine could be operated safely and the contained water could be pumped out in a controlled manner.

\section{1 Plug locations}

The locations for the water plugs were influenced by the surrounding workings, planned underground mining activities, open pit design and schedule, geological structures and rock mass conditions in the 130 decline. The impact of these was discussed during a risk-based review, to determine the adequacy of the proposed flood protection measures.

Assessment of the under-pit water storage and pit catchment identified the requirement for three plugs as follows:

- VR2D plug: This was required to isolate the VR2C raise which is connected to the bottom of the Main Dome Stage 3 pit. The VR2C plug was decommissioned and the next suitable location for a plug was in the next leg of the raise which was VR2D. This plug is $440 \mathrm{~m}$ below surface with a design head of $180 \mathrm{~m}$.

- 5094 decline plug: This plug is in the lower section of the I30 decline and was designed to isolate the water flowing down the decline from the connections to the open pit. The location of this plug was influenced by the planned mining activity on the M40, M35 reefs and the Stage 3 pit design. This plug is $406 \mathrm{~m}$ below surface with a design head of $150 \mathrm{~m}$.

- 5172 plug: This plug was designed to stop water flowing up the 130 decline and into the cave via a connection at the 130 workshop. If water flowed into the cave then it would report to the draw points and short circuit the flood defences. This plug is $328 \mathrm{~m}$ below surface with a design head of $70 \mathrm{~m}$.

\section{2 Plug type}

All three plugs were to be constructed out of concrete. The plugs were designed as parallel plugs. Parallel plugs do not require a wedge to be cut out of the rock and rely on the rough interface between the rock and concrete for shear resistance. This method was preferred as the rock is strong, uneven and has rough surfaces which provide a good interlock. Scaling and floor stripping conducted confirmed that the decline plugs would be well locked in. The VR2D plug was to be constructed in a bored raise which had a smooth profile. This plug was designed with a foundation so that it did not rely on frictional resistance for support.

\section{3 Design methodology}

The design methodology was based on the previous design of water retaining plugs at Telfer, namely the VR2C plug and the I30 decline plug (Maunsell, 2004). The designs were based primarily on a paper titled, "Permanent Sealing of Tunnels to Retain Tailings or Acid Rock Drainage" (Lang, 1999). A summary of the failure modes are listed in Section 4.1 and example calculations for the 5172 plug are provided in Appendix A.

Further design checks were carried out using a circular published by the UK HSE (2005) titled, "The Design and Construction of Water impounding Plugs in Working Mines". Plug related publications were also used to assess the design, including papers by Auld (1982), Chekan (1985) Harteis et al. (2008) and Pacovsky (1999). 


\section{4 Use of shotcrete as plug construction material}

The decision to use shotcrete instead of mass poured concrete was influenced by previous site experience of mass poured concrete. The two previous plugs on site were constructed using mass poured concrete and had a few problems, as follows:

1. Barricade failure due to high head of uncured concrete.

2. Logistics on continuously supplying concrete for a mass pour were difficult and resulted in a cold joint in one plug. The cold joint subsequently showed seepage when the plug was subjected to a head of water.

3. Complete filling to the backs was difficult for the decline plug and it was difficult to confirm if the subsequent grouting had achieved tight filling.

4. Mass concrete curing resulted in shrinkage at the concrete/rock interface which was remedied by grouting but it was difficult to confirm the success of this.

The use of shotcrete alleviated some of these issues but posed challenges of its own. The advantages of using shotcrete were as follows:

1. Extensive and high load bearing formwork was not required. The safety concerns of formwork failure and exposure to a head of wet concrete were removed.

2. The shotcrete could be sprayed in sub-vertical layers allowing for overnight curing between sprays and some heat dissipation. Thus there was no major logistical planning required to ensure mass supply of concrete as would be required for a mass pour.

3. Shotcrete spraying would result in good bond with the rock and good compaction of the concrete.

4. Fibres in the shotcrete would reduce shrinkage effects and add toughness.

5. The logistics of spraying shotcrete was well understood by mine personnel and there was substantial experience in this methodology.

There were a few challenges with using shotcrete. These were as follows:

1. Mix design: Shotcrete mix has higher cement content and as such would generate more heat.

2. Cold joints: Shotcrete layer thickness would be approximately $1 \mathrm{~m}$ thick and could result in numerous sub-vertical cold joints.

3. Quality: Shotcrete quality is dependent on more variables than for poured concrete, including quality of the mix, equipment, air pressure, slump, admixtures and accelerator dosage.

4. Nozzleman: Shotcrete quality is highly dependent on the expertise of the nozzleman. The skill of the nozzleman is the most significant factor.

These challenges were addressed through the following actions:

1. Mix design: A shotcrete specialist, Dr Stefan Bernard from The Shotcrete Engineers (TSE) was engaged to design a mix that could be sprayed and would generate lower heat. Trial mixes were sprayed at the TSE laboratory to identify the best recipe for a workable shotcrete mix which had low heat dissipation (Bernard, 2010). This mix was then tested on site to verify performance with site aggregates and under site conditions. The mix was instrumented with thermometers during the testing and also during the plug spraying to track temperature changes and confirm that the mix was performing as planned.

2. Cold joints: This was remediated by using fibres in the shotcrete to provide bonding between layers and by high pressure washing between spraying to clean the surface so that good bonding occurs. The joints would also be sub-vertical and at steep angles to the leakage path. 
3. Quality: The contractors on site, Jetcrete Pty Ltd, supplied a new Normet Spraymec machine for this project. This type of machine is used on site and as such there was extensive site experience on operating and maintaining this machine. The mine supplied compressors to boost air pressure and volume to the plug construction sites. The shotcrete was batched using a dedicated and experienced batcher from Jetcrete. A quality management plan was drawn up by TSE with requirements for testing and monitoring. An experienced Newcrest technician was dedicated to the project to conduct testing and monitoring.

4. Nozzleman: The Jetcrete nozzlemen, Mark Gator and Gordon Geddes, were enrolled in the EFNARC certification programme and they were certified as EFNARC accredited nozzlemen (EFNARC, 2011). They both proved to be exceptional nozzlemen with the added benefit of bringing extensive experience and trouble shooting ability to the project.

\section{Site investigation}

Site investigation was conducted to quantify geological and geotechnical conditions at the proposed plug locations and collect data for plug design.

\section{1 The 5172 plug location}

The decline at the 5172 plug area was dry with no dampness or signs of water flow. The rock is a sandstone/siltstone unit which has unconfined compressive strengths (UCS) in excess of $200 \mathrm{MPa}$. The decline had been mapped during construction and there was a historic scan line mapping data of the decline in that area. The decline was heavily scaled using a jumbo to expose fresh rock. This resulted in most of the surface of the rock being scaled back to 100 to $250 \mathrm{~mm}$. The scaled rock showed that the few geological features in the area were very competent and the rock mass in general was of good quality.

The principal geological features were bedding planes and bedding related veining. There were also a few long joints which were sub-vertical and one set of west dipping long joints and veins (Figure 2). The joints and bedding related veins were tight with 2 to $5 \mathrm{~mm}$ of hard infill (quartz, carbonate) in the veins.

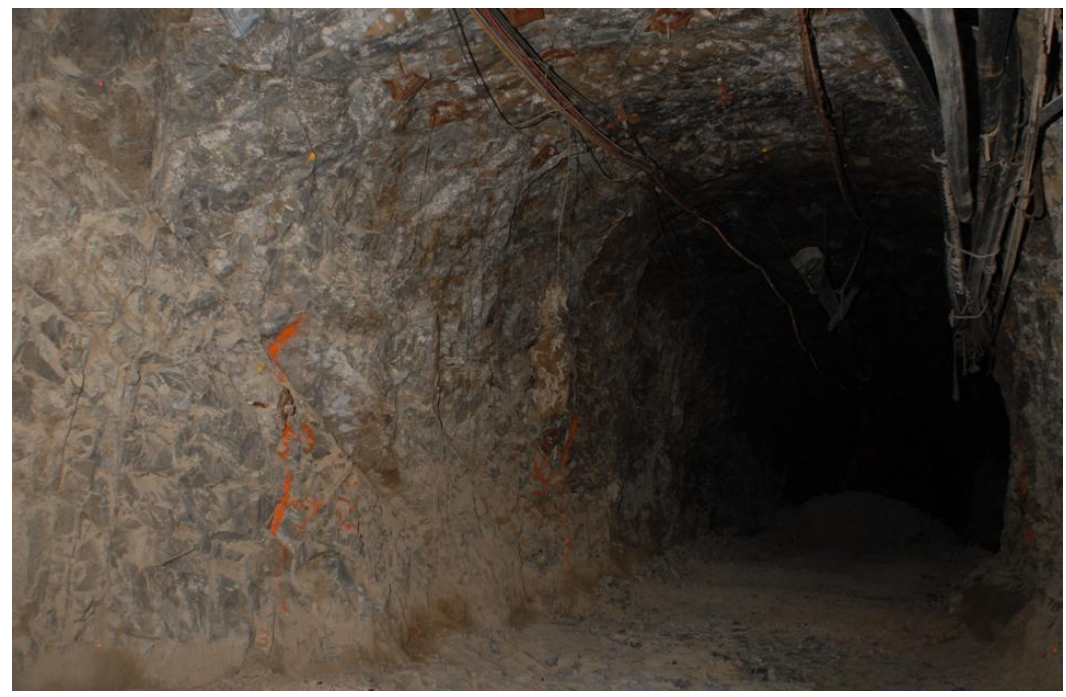

Figure 2 Photograph of the site for the $5172 \mathrm{plug}$, south wall. Note the heavy scaling and rattle marks (these services were removed before spraying the brattice)

The mapping data and assessment of the scaled areas were used to classify the rock mass. The scaling created a very uneven surface with many joint planes. However, close inspection of these indicated that most of the short planes where generated from blast damage around the drive. Generally the rock mass was of excellent condition and the scaling had resulted in clean rock with a very rough and undulating surface, ideal for the concrete to key into the rock (Figure 2). 
Bieniawski's RMR (Bieniawski, 1976) was used to classify the rock mass as there was precedence in this classification being used in plug design (Table 1). The rock was classified as good rock with an $\mathrm{RMR}_{76}$ of 75 .

\section{2 The 5094 plug location}

The decline in the 5094 plug area was generally dry with a few damp structures on the west side (upstream side) of the plug and other structures which had limonite staining and weathering on the wall rock, indicating that these structures were water bearing at some stage. The rock unit comprised of sandstone and siltstones with a UCS in excess of $200 \mathrm{MPa}$. The decline was mapped during construction and the plug location was remapped. A scan line mapping of the northern wall was also conducted. The plug location was moved approximately $3 \mathrm{~m}$ downstream from the original plan to site it further away from an altered fault zone (Figure 3). The condition of this fault zone indicated that it could transmit water and the location of the west dipping veins indicated that these could provide a conduit for the water. Formation grouting was recommended to seal the structures passing through the plug.

The decline was heavily scaled using a jumbo to expose fresh rock. This resulted in most of the surface of the rock being scaled back to 100 to $250 \mathrm{~mm}$. The scaled rock confirmed that there were a few geological features in the area but these were more competent then the mapping indicated.

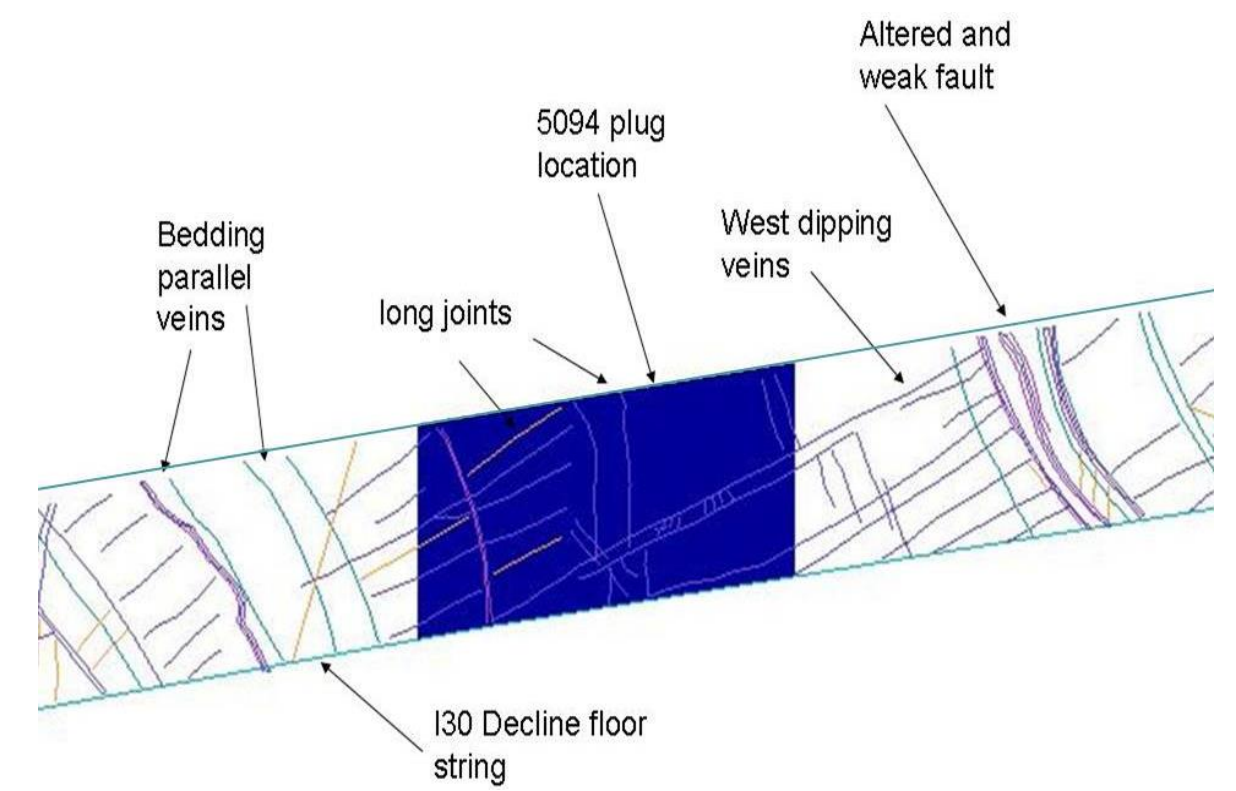

Figure 3 Section view (looking north) showing the plug location and mapping on the southern wall of the decline

The scan line data was used to classify the rock mass. Generally the rock mass was of good condition but it contained numerous long joints and bedding related veins. These were generally tight or had hard quartz/carbonate infill. Some of these also had limonite staining indicating movement of water. The rock mass up-dip from the plug was strongly influenced by a large fault zone and the rock mass down-dip from the plug had increasing density of structures (Figure 3). Scaling had resulted in clean rock with a very rough and undulating surface, ideal for concrete to key into the rock. Bieniawski's RMR (Bieniawski, 1976) was used to classify the rock mass as there was precedence in this classification being used in plug design (Lang, 1999). The rock was classified as good rock with an $\mathrm{RMR}_{76}$ of 65.

\section{$4 \quad$ Design of the 5172 plug}

\section{1 Failure modes}

Design calculations were carried out for the following failure modes: 
1. Shear failure (both static and dynamic) through:
a. Concrete
b. Concrete-rock interface
c. Rock.

2. Deep beam bending

3. Hydraulic jacking

4. Seepage (including grouting requirements)

The impact of bearing failure was also investigated (Auld, 1982). However, the bearing strengths of concrete and rock are more than three times the shear strength and as such this was not used in the calculations as both materials would fail in shear well before bearing failure. An example of the design calculations is shown in Appendix A.

\section{2 Rock mass conditions and hydraulic gradients}

The rock mass conditions were classified to evaluate plug stability against shear failure through rock, rockconcrete interface and the hydraulic gradient (change in head along flow path) through the rock. The principal criteria for assessing the hydraulic gradient were through use of data published in a paper by Lang (1999) which is reproduced in Table 1 below.

Table 1 Design parameters derived from rock mass classification (after Lang, 1999)

\begin{tabular}{ccc}
\hline $\begin{array}{c}\text { Rock Mass } \\
\text { Classification } \\
\text { RMR76 }\end{array}$ & $\begin{array}{c}\text { Design Shear } \\
\text { Strength } \\
\text { (KPa) }\end{array}$ & $\begin{array}{c}\text { Allowable } \\
\text { Hydraulic } \\
\text { Gradient }\end{array}$ \\
\hline $\begin{array}{c}\text { Very good rock } \\
81<\mathrm{RMR}<100 \\
\text { Good rock }\end{array}$ & 1500 & $15-30$ \\
$61<\mathrm{RMR}<80$ & 900 & $10-14$ \\
$\begin{array}{c}\text { Fair rock } \\
41<\mathrm{RMR}<60\end{array}$ & 600 & $7-9$ \\
Poor rock & & \\
$21<\mathrm{RMR}<40$ & 300 & $5-6$ \\
Very poor rock \\
$\mathrm{RMR}<20$
\end{tabular}

\section{3 Summary of design outcomes}

The designed outcomes for the plug are summarised below:

- Design head $=70 \mathrm{~m}$

- Plug length $=6 \mathrm{~m}$

- Construction $=$ formwork + shotcrete $(U C S$ of $25 \mathrm{MPa})$

- Volume of shotcrete $=$ nominal $260 \mathrm{~m}^{3}$

Thermal expansion during plug curing and subsequent contraction has the potential to crack the concrete and increase leakage. Low strength concrete $(25 \mathrm{MPa})$ was specified as a means to limit the cement content 
and the resultant heat generated during curing. Shotcrete specifications and mix design are discussed in Section 5.4. Grouting was not a design requirement but was recommended as a precautionary measure. Grouting requirements:

1. $0.7 \mathrm{MPa}<$ grouting pressure $<1.8 \mathrm{MPa}$

2. Grouting to be conducted after the plug was constructed and cured for at least seven days.

3. Grouting hole configuration and grout specifications are shown in Figure 5.

\section{$5 \quad$ Construction of the 5172 plug}

\section{1 Site preparation}

Site preparation was conducted by stripping the services and thoroughly scaling the rock with a jumbo. The road base was removed from the floor for the plug length, plus $3 \mathrm{~m}$ either side. The floor was also scaled with a jumbo. The area was washed down and barricaded off.

\section{2 Formwork construction}

Formwork was constructed using techniques similar to site practice for constructing shotcreted ventilation brattices. The heading was check scaled before re-entry. Bolts were installed in the walls backs and walls while the jumbo was scaling during site preparations. Chains were fixed between these bolts and tensioned. Mesh was attached to the chains and hessian was attached to the mesh. A second layer of mesh was attached to sandwich the hessian and provide a surface for shotcrete spraying (Figure 4).

During spraying a rebound mat made out of conveyor belts was placed on the floor to keep the shotcrete rebound from building up on the cleaned floor. The formwork was sprayed to $500 \mathrm{~mm}$ thickness and allowed to cure for 24 hours before plug spraying commenced.

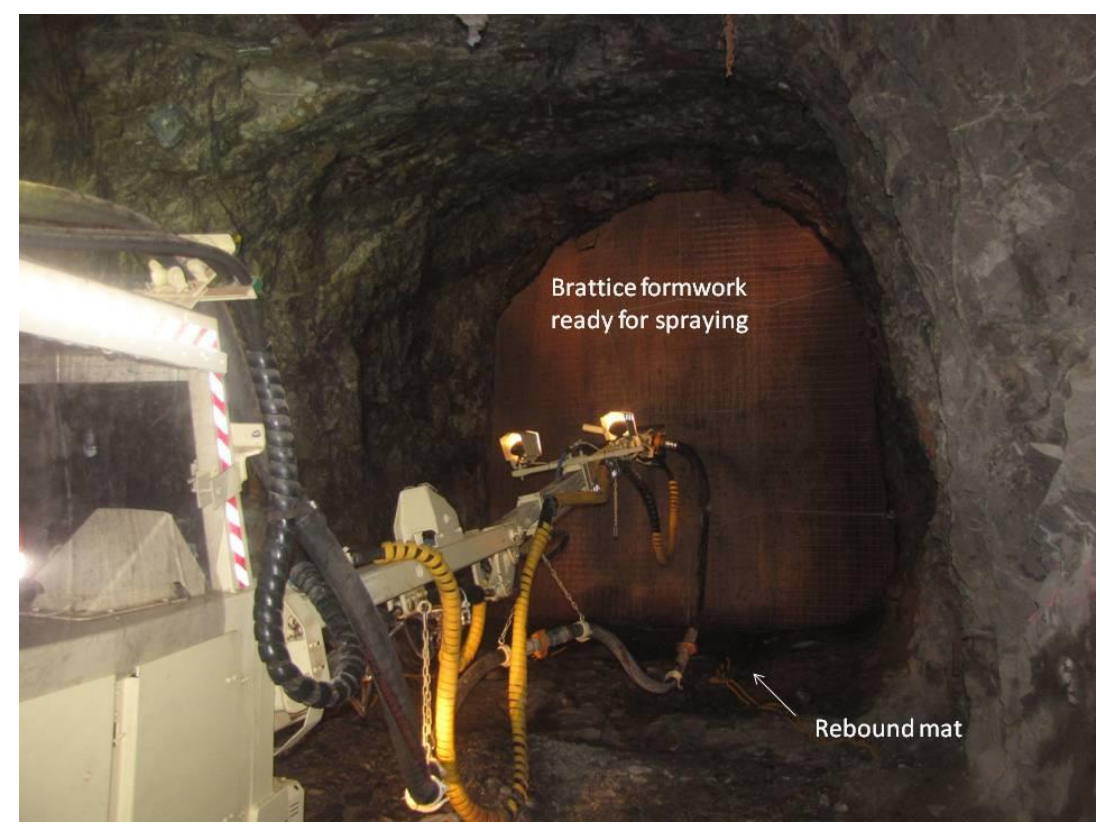

Figure 4 Photograph of the 5172 brattice formwork ready for spraying

\section{3 Instrumentation}

The temperature of the sprayed plug was monitored relative to the surrounding rock temperature. This was achieved by installing a thermometer in a bore hole near the plug to measure the rock temperature. Two thermometers were installed on the plug face (one on the left and one on the right) at two locations during 
spraying; the first about $2 \mathrm{~m}$ from the wet side and the second about $2 \mathrm{~m}$ from the dry side of the plug. Data loggers were set up to take readings every hour. The data was downloaded daily using a memory stick.

The concrete samples and test cylinders were also monitored and stored in controlled water baths on site which had thermostats and temperature regulators to ensure that the samples were cured at $40^{\circ} \mathrm{C}$ to simulate plug conditions.

\section{4 Shotcrete mix design}

Once a trial mix was developed at the TSE laboratory, site trials were carried out underground to confirm that the mix would work using site aggregates and under site conditions. Slight changes were made to the mix during site trials.

One of the requirements for the mix design was that the temperature increase during hydration should not exceed $30^{\circ} \mathrm{C}$ above the rock temperature. Final site trails were completed on the 1 July and temperature measurements were taken for the next four days. The mix temperature did not exceed $15^{\circ} \mathrm{C}$ above rock temperature.

It is acknowledged that the trial had significantly less concrete then what was to be sprayed into the plug. Therefore the concrete temperature was expected to be higher in the plug than what was recorded in the trials.

The final mix design used for the 5172 plug is shown in Table 2.

Table 2 Final mix design used for the 5172 plug

\begin{tabular}{lc}
\hline Coarse sand & $815 \mathrm{~kg}$ \\
Fine sand & $296 \mathrm{~kg}$ \\
$10 \mathrm{~mm}$ aggregates & $86 \mathrm{~kg}$ \\
$7 \mathrm{~mm}$ aggregates & $343 \mathrm{~kg}$ \\
LH cement & $100 \mathrm{~kg}$ \\
GP cement & $100 \mathrm{~kg}$ \\
Fly-ash & $150 \mathrm{~kg}$ \\
Silica fume & $20 \mathrm{~kg}$ \\
Air entrainer (Micro-air 940 ) & $500 \mathrm{ml} / \mathrm{m}^{3}$ \\
Super plasticiser (Rheo Build 1000) & $1,000 \mathrm{~mL}$ \\
Retarder (Delvocrete) & $1,000 \mathrm{~mL}$ \\
Fibre & $6.5 \mathrm{~kg}$ (Barchip shogun) \\
\hline Target slump at the batch plant & $110 \mathrm{~mm}$ \\
Slump underground & 85 to $100 \mathrm{~mm}$ \\
Temperature (ex batch plant) to be nominal $20^{\circ} \mathrm{C}$ & \\
\hline
\end{tabular}

Chilled water was used at the batch plant to keep the temperature around $20^{\circ} \mathrm{C}$.

Remedial measures were predetermined for the following scenarios:

1. Loss of slump. Micro-air 940 and a measuring jug were stored at the plug site. If the slump was below target, 2 litres of Micro-air 940 was added to the agitator and mixed at high revolution for three minutes. This lifted the slump measurement. If it lifted the slump to above the target range, 
that was not a problem as the micro-air was expelled during spraying and the mix sprayed well and set well as the micro-air did not change the chemistry.

2. Shotcrete is not standing up. The amount of Delvocrete added was to be reduced to $500 \mathrm{~mL} / \mathrm{m}^{3}$ and the Rheo Build 1000 was to be removed from the mix. This remedial action was not required during construction.

\section{5 Shotcrete application}

The plug was constructed with shotcrete layers applied in the following cycle:

1. Hydro-scale the backs, walls and floor and remove all rebound and loose material.

2. Wash the face with high pressure water to remove dust and concrete powder but do not scale the shotcrete.

3. Remove any pooled water and loose material on the floor and blow it clean using an air hose.

4. Check that the rebound mat is located on the floor so that it will catch the rebound but is just over a metre from the face so that it does not get sprayed into the face.

5. Spray shotcrete on the face to about $1 \mathrm{~m}$ thick, ensuring that the face is kept sub-vertical and steeper than $70^{\circ}$.

6. Allow at least 12 hours of curing.

7. Ensure that the face has achieved $1 \mathrm{MPa}$ in strength using a Meyco Penetrometer, before the next layer is sprayed.

8. Move the rebound mat.

9. Repeat the cycle.

\section{6 Grouting}

Grouting was conducted to seal the rock around the perimeter and the rock/shotcrete interface. Grouting was conducted after the shotcrete was allowed to cure for a week. Holes were drilled around the perimeter of the plug starting in the plug face and angled out as shown in Figure 5. Calculations for grouting pressures are shown in Appendix A. Resin grouting was chosen due to prior experience with the product and the tight rock jointing.

Stand pipes were grouted into the holes and resin injection was conducted such that the shotcrete/rock interface was grouted first and then the rock was grouted under pressure.
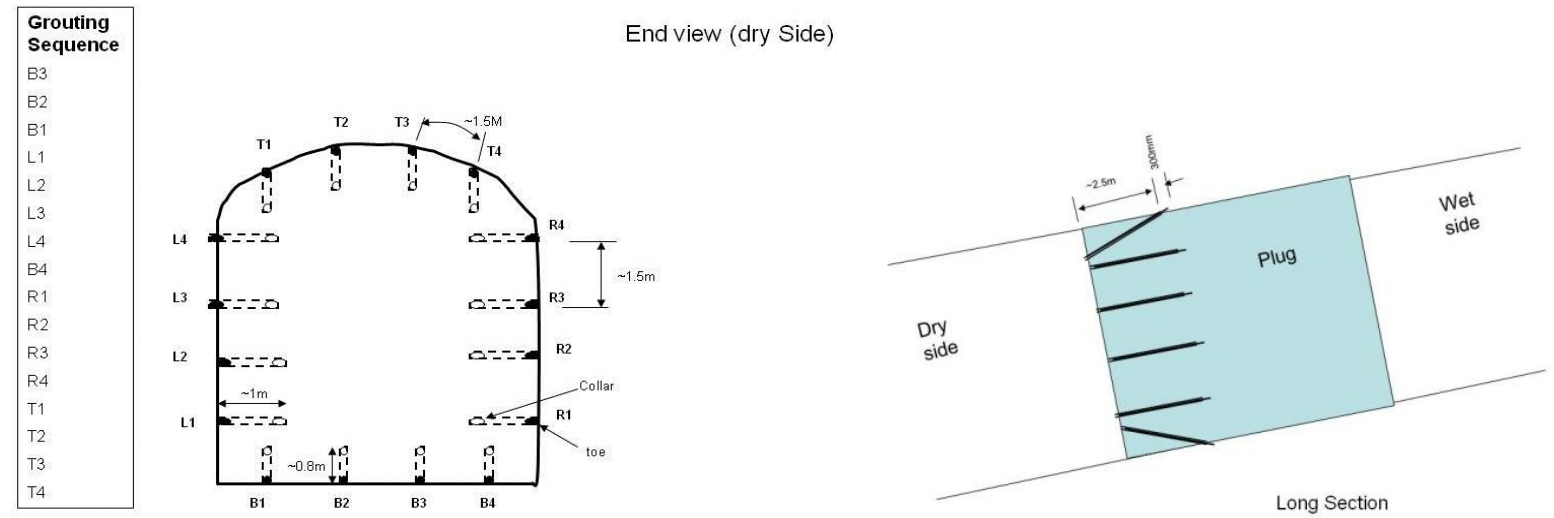

Figure 5 Grout hole design for plug tightening 
A quality management plan was implemented which included checks and signoff at each stage of the construction. It also specified the minimum specifications, measurements required, samples to be collected and test work to be carried out.

The quality management included the complete supply chain from batch plant to the face. At the batch plant, the weighing scales were calibrated, aggregate grading curves were verified against design, certification for cement, fly-ash and admixtures were verified and agitator bowls were inspected.

At the start of every shift a standard Jetcrete prestart check was carried out which also included records on weather conditions, rainfall and temperature readings, chilled water temperature, audit of the amount of material on site, a check on the agitator and a verification of the mix design entered in the batching computer. The aggregate stockpiles where also turned over to mix the aggregates and achieve an even distribution of moisture in the aggregate pile.

A complete batching record was kept for every batch and a slump test was conducted on site for the first batch of the shift to verify slump and to tweak the water requirements for the day. Further slump tests were to be taken if there was significant change in conditions such as rainfall or change in moisture content in the aggregates.

No additional water was added in transit, and the transport time was recorded to calibrate slump loss.

The plug site preparations were also checked before spraying to ensure that the rebound mat was in the correct place, the walls and face were cleaned and the face wetted, all loose rock and water had been blown off the floor, and photographs had been taken. The QAQC technician was required to sign off on the face preparation before it could be sprayed.

The technician also recorded the air temperatures (wet and dry bulb) before spraying, and conducted a slump test on the delivered shotcrete, and collected samples for laboratory testing. The nozzleman also visually inspected the mix to verify its suitability for spraying.

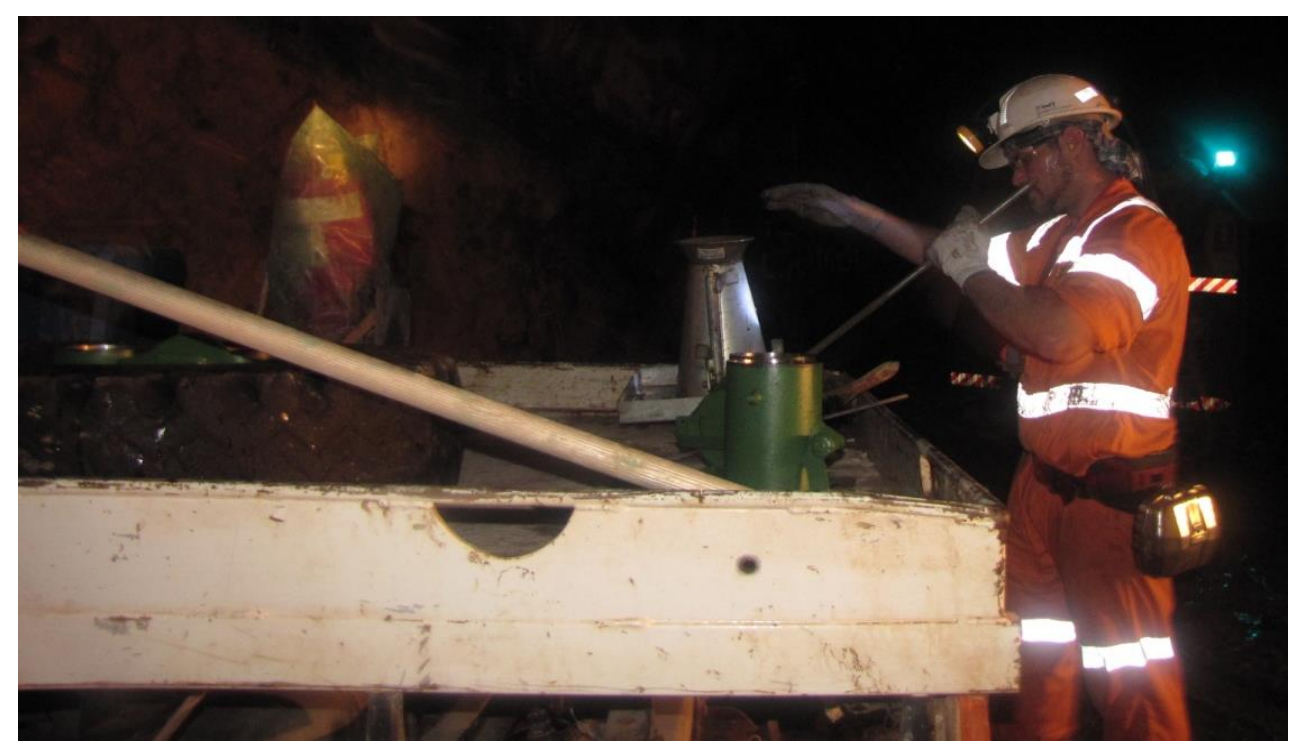

Figure 6 Slump testing and sample collection at the plug site

\section{Design and construction of the 5094 plug}

The 5094 plug was designed and constructed in a similar manner to the 5172 plug. The learnings from the 5172 plug construction were used to improve the construction of the 5094 plug. 
The most significant difference between the two plugs was that the 5094 plug had a design head of $150 \mathrm{~m}$ and as such was considerably longer than the 5172 plug. The plug location also had more geological structures in the vicinity.

The design required the 5094 plug to be $11 \mathrm{~m}$ long. This gave rise to a few challenges in regards to heat generation from the mass of shotcrete and potential for cracking due to thermal expansion and subsequent contraction.

In order to mitigate these problems, a steel duct was designed to go in the middle of the plug to reduce the amount of shotcrete used and to assist in heat dissipation (Figure 7). The steel duct was designed by structural design engineers and had a specially fabricated bulkhead door, similar to that used for pressure vessels and submarines. This allowed for inspection of the upstream side of the plug (Figure 8).

Due to the presence of faults on the upstream side and potential for linking structures, an additional stage of grouting was implemented in the middle of the plug. This grouting was designed to seal the rock and geological structures around the plug and increase the stream path required for any potential leaks.

After the completion of the plug, the steel duct/shotcrete interface was grouted through specially prepared grouting lugs to ensure that the interface was sealed, and that any shotcrete shadows behind the steel duct flanges and bearing plates were completely filled.

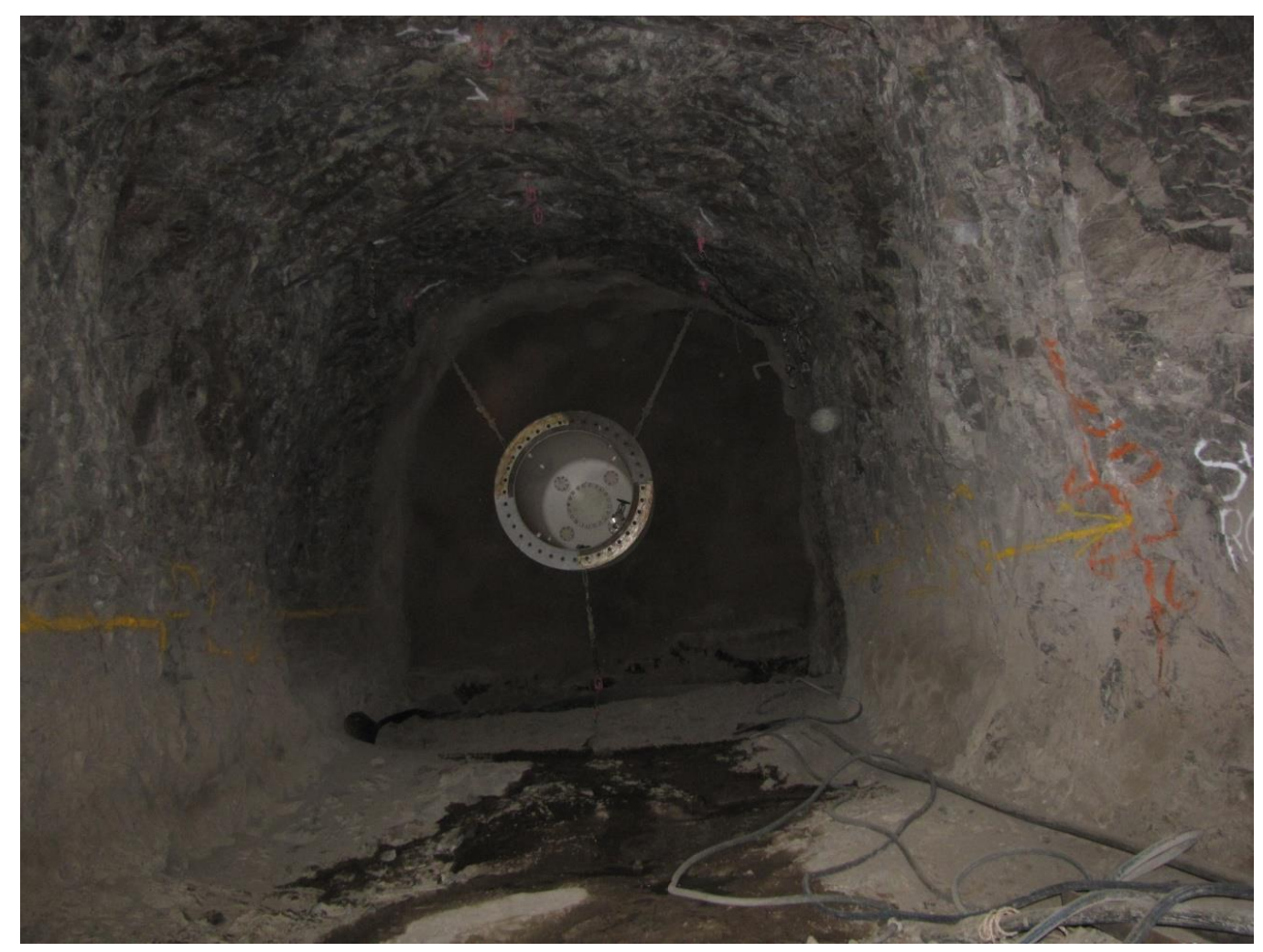

Figure 75094 plug brattice formwork sprayed and ready to commence spraying the plug. Note the steel duct in the centre of the plug for heat dissipation and access through the plug 


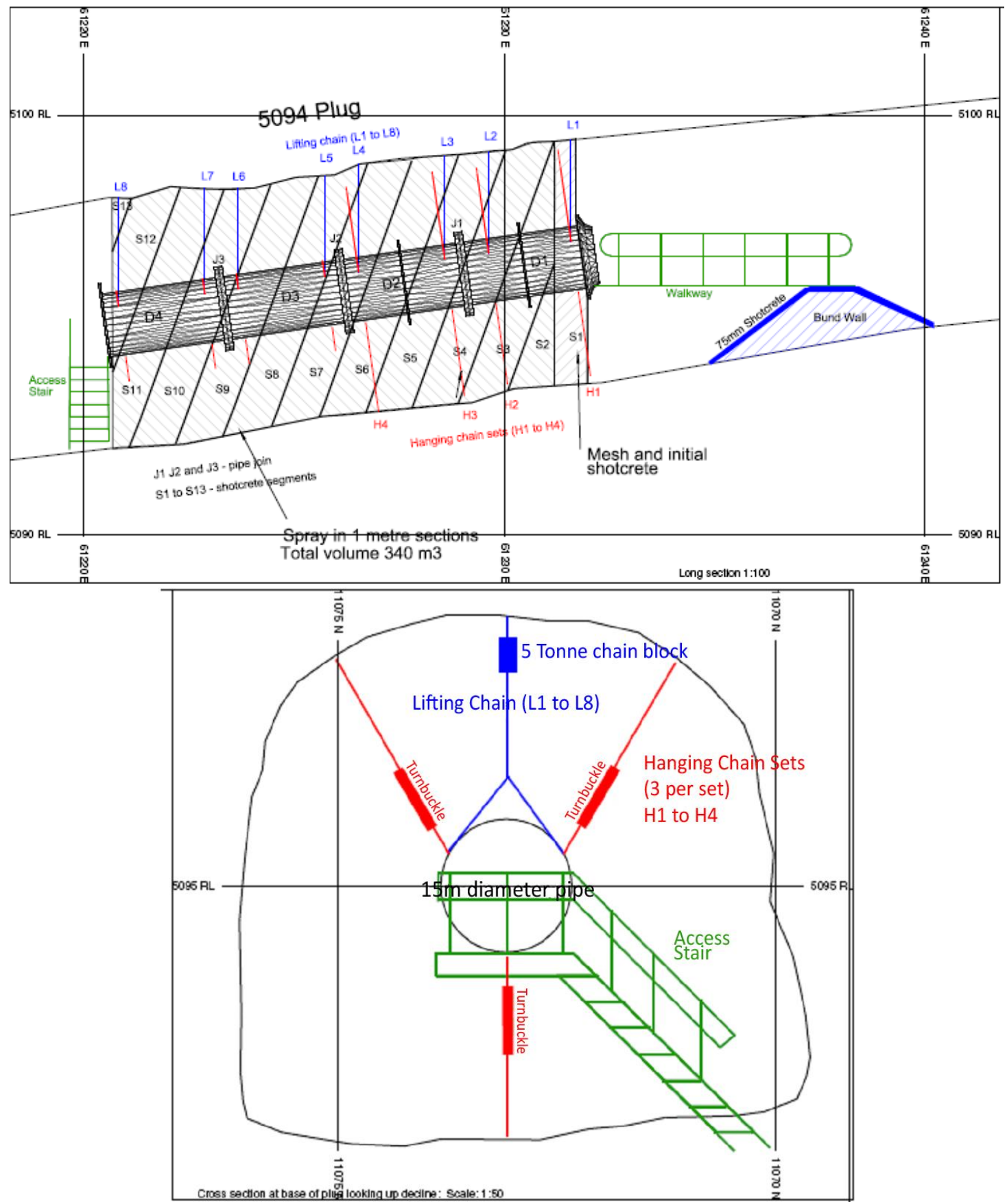

Figure 85094 plug, side and face elevation showing steel duct and ladderways

\section{Discussion}

The design methodology for concrete water plugs is covered by several excellent papers by South African exponents of the craft and by Lang (1999). There is also a UK design guideline which is used for coal but is easily adopted for hard rock mining.

The construction of water plugs using shotcrete had fewer uncertainties compared to mass poured plugs as the plug construction could be examined on every metre advance. It was also a much safer and logistically simpler method of construction as it did not require construction of barricades designed to hold back masses of wet concrete, and it also did not require a continuous supply of concrete for the mass pour. Previous experience on site has identified these as major challenges for plug construction. 
Using sprayed concrete also provided improved seal between the concrete and rock, and improved compaction compared to a mass pour. The fibres in the shotcrete also assisted in reducing shrinkage and redistributing stresses.

However, the successful construction of the plug was heavily dependent on the correct mix design, quality batching, highly experienced nozzlemen and rigorous quality control. The work done by TSE in developing the mix design, verifying the temperature changes and back analysing the actual shotcrete performance was critical in ensuring success. Jetcrete provided excellent support to the project by supplying near new spraying equipment and agitator trucks for the work, and providing highly experienced batchers and highly skilled nozzlemen.

The shotcrete spraying was conducted during night shift, taking advantage of reduced traffic in the decline and lower surface temperatures. It also allowed the construction of the drainage system and related site works to continue in parallel during the day shift. The plug face was also measured by the surveyors to keep track of progress and any corrective actions were finalised during the day.

An experienced technician and project engineer were dedicated full time to the project to ensure that quality was maintained and construction proceeded without delay.

The mix used generated less heat than standard shotcrete and sprayed well, however, it did not reach the required $25 \mathrm{MPa}$ in 28 days. In situ cores were taken from the 5172 plug and tested to verify that the design strengths had been achieved. The cores exceeded the $25 \mathrm{MPa}$ requirements when tested at 59 days. The longer time taken to achieve full strength was not considered to be detrimental as this allowed for cementitious bond formation to continue while the plug cooled. This would have contributed to repairing any micro-cracking during cooling and facilitated redistribution of stresses.

The drainage related construction activities that were being conducted simultaneous to the plug construction included: construction of settlement bunds to manage sedimentation, drainage holes with filter screens and specially designed valve train facilities (Figure 9) for pumping out the impounded water. These were remote controlled from the surface mine control centre and included telemetry for monitoring water levels and pressure heads. These activities had to be sequenced carefully in order to construct the water containment and pumping system to design and to schedule. Careful design and construction of this infrastructure were critical to the management of impounded water and mine dewatering.

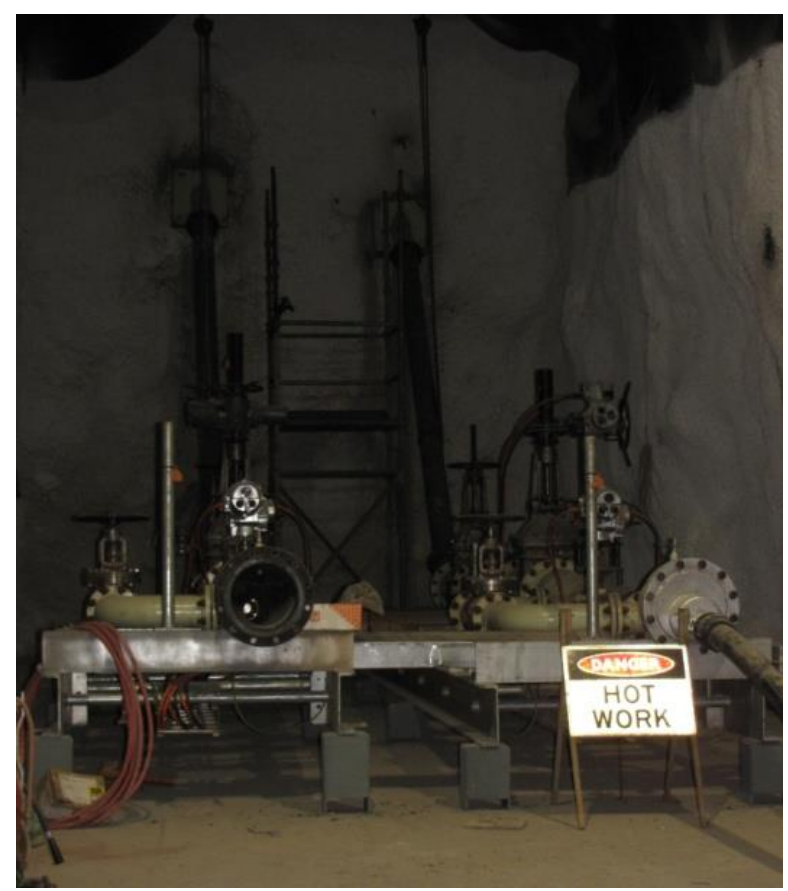

Figure 9 Photograph of the valve train for the drainage system, under construction 
A new set of water containment plugs were required to manage the Telfer under-pit water as the open pit mined down through the old defences. The site had prior history with constructing water containment plugs using mass poured concrete. These had been difficult to construct and had not performed to design capability.

It was decided that some of the short-comings of the poured plugs could be overcome by using sprayed concrete. This was simpler to construct and provided very good seal against the rock, however, it required technical expertise in designing a suitable mix which could be sprayed against a wall but did not generate excessive heat. It also required skilled personnel in shotcrete batching, spraying and quality control.

The plugs were successfully constructed with minimum disruptions to operations, and to design specifications. The mix performed to expectation and good quality control was achieved.

\section{Acknow l edgements}

The authors acknowledge the mix design expertise provided by Dr Stefan Bernard, the skills and experience of Jetcrete staff in general, and Mark Gator in particular, Byrnecut Mining in general and Adrian Short in particular, CDC Contracting, Wilshaw Engineering and all the Newcrest personnel who put in the extra effort to make the plug construction a success. The authors also thank the mine manager for his support and the Newcrest management for permission to publish this paper.

\section{References}

ACl (1972) Building Code Requirements for Structural Plain Concrete. American Concrete Institute (ACl 322-72)

AS1170.4 (2007) Structural Design Actions Part 4. Earthquake Design in Australia. Australian Standard, 2nd Edition.

Auld, F.A. (1982) Design of underground plugs, International Journal of Mining Engineering, Chapman \& Hall Ltd, Vol. 1, pp. 189-228.

Bernard, E.S. (2010) Laboratory Investigation for Low Heat Shotcrete for Plug Construction in Newcrest Mines. TSE Report \#208. Internal Report to Newcrest Mining Ltd dated July 2010.

Bieniawski, Z.T. (1976) Rock mass classifications in rock engineering, in Proceedings of the Symposium on Exploration for Rock Engineering, Z.T. Bieniawski (ed.), A.A. Balkema (eds), Rotterdam, pp. 97-106.

Chekan, G. (1985) Design of bulkheads for controlling water in underground mines, Information circular 9020 Bureau of Mines, United States Department of Interior, Technology \& Engineering, $36 \mathrm{p}$.

Dixon, R.A., Singh, U. and McArthur, C. (2010) Interaction between a propagating cave and an active pit at Telfer Mine - Part II: Monitoring Interaction, in Proceedings 2nd International Symposium on Block and Sublevel Caving (Caving 2010), Y. Potvin (ed), 20-22 April 2010, Perth, Australia, Australian Centre for Geomechanics, Perth, pp. 321-332.

EFNARC (2011) Experts for Specialised Construction and Concrete Systems, @2011 EFNARC, viewed 10 November 2011, http://www.efnarc.org/Nozzleman_Certification_Scheme.html.

Garrett, W.S. and Campbell Pitt, L.T. (1961) Design and Construction of Underground Bulkheads and Water Barriers. Transactions of the 7th Commonwealth Mining and Metallurgy Congress, South African Institute of Mining and Metallurgy.

Harteis, S.P., Dolinar, D.R. and Taylor, T.M. (2008) Guidelines for permitting, construction and monitoring of retention bulkheads in underground coal mines, Information circular 9506, Department of Health and Human Services, National Institute for Occupational Safety and Health, Pittsburgh, USA.

Lang, B. (1999) Permanent sealing of tunnels to retain tailings or acid rock drainage, in Proceedings Mine, Water \& Environment II, Congress of the International Mine Water Association, Sevilla, R. Fernández Rubio (ed.), pp. 647-655

Maunsell Australia Pty Ltd (2004) Plug Design, Telfer, Design and calculations sheets for the I30 and VRC plugs, Internal design worksheet dated 30/1/2004, Newcrest Mining Ltd.

Pacovsky, J. (1999) Continuous measurement of stress and temperature during testing of a fibre shotcrete pressure plug, Journal of Geotechnical and Geological Engineering, Kluwer Academic Publishers, Netherlands, Vol. 17, pp. 335-349.

Singh, U., Dixon, R.A. and McArthur, C. (2010) Interaction between a propagating cave and an active pit at Telfer Mine - Part I: Interaction Management, in Proceedings 2nd International Symposium on Block and Sublevel Caving (Caving 2010), Y. Potvin (ed), 20-22 April 2010, Perth, Australia, Australian Centre for Geomechanics, Perth, pp. 307-320.

UK HSE (2005) United Kingdom Health and Safety Executive. The design and construction of water impounding plugs in working mines, Issue date 15th July 2003, viewed at http:/www.hse.gov.uk/mining/circulars/waterplu.htm. 


\section{Appendix A}

\section{Decline plug calculation}

\begin{tabular}{ll}
\hline Design Parameters & \\
\hline Design for mass concrete (shotcrete): & $25 \mathrm{Mpa}$ \\
Design concrete UCS & $840 \mathrm{KPa}$ \\
Concrete allowable shear stress equivalent to UCS of $25 \mathrm{Mpa}$ (ACl 1972) & Fair to good rock \\
\hline Rock mass classification & $61<\mathrm{RMR}<80$ \\
& $900 \mathrm{KPa}$ \\
Design shear strength (Table 1) & 10 to 14 \\
Allowable hydraulic gradient (Table 1) & No keying required \\
Design for parallel plug & $70 \mathrm{~m}$ \\
\hline
\end{tabular}

\begin{tabular}{|c|c|c|}
\hline \multicolumn{3}{|l|}{ Static Loading } \\
\hline \multicolumn{3}{|l|}{$\begin{array}{l}\text { Punching shear } \\
\text { Shear strength of concrete }<\text { rock. Therefo }\end{array}$} \\
\hline Design factor of safety for static loading & & 4 \\
\hline Resisting force & $=$ & $2 *(h+w) * L^{*} U$ \\
\hline Driving force & $=$ & $\rho * g * H^{*} w^{*} h$ \\
\hline \multicolumn{3}{|l|}{ Where } \\
\hline $\mathrm{h}$ & $=$ & Tunnel height \\
\hline & $=$ & $6 \mathrm{~m}$ \\
\hline w & $=$ & Tunnel width \\
\hline & $=$ & $6 \mathrm{~m}$ \\
\hline 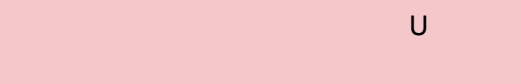 & $=$ & $\begin{array}{l}\text { Allowable shear strength of } \\
\text { weakest material }\end{array}$ \\
\hline & $=$ & $\begin{array}{l}840 \mathrm{KPa} \text { (for concrete with UCS } \\
=25 \mathrm{MPa} \text { ) }\end{array}$ \\
\hline $\mathrm{H}$ & $=$ & Head of water $(m)$ \\
\hline$\rho$ & $=$ & Density $\left(\mathrm{kg} / \mathrm{m}^{3}\right)$ \\
\hline & $=$ & $1000 \mathrm{~kg} / \mathrm{m}^{3}$ for water \\
\hline $\mathrm{g}$ & $=$ & $9.81 \mathrm{~m} / \mathrm{s}^{2}$ \\
\hline For FOS & $=$ & 1 \\
\hline Resisting force/driving force & $=$ & 1 \\
\hline Resisting force & $=$ & $2 \mathrm{E}+07 \mathrm{~L}$ \\
\hline Driving force & $=$ & $2.5 \mathrm{E}+07$ \\
\hline $\mathrm{L}$ & $=$ & 1.23 \\
\hline \multicolumn{3}{|l|}{ Check units } \\
\hline $\mathrm{kg} / \mathrm{m}^{3 *} \mathrm{~m} / \mathrm{s}^{2 *} \mathrm{~m}^{*} \mathrm{~m}^{*} \mathrm{~m} /\left(\mathrm{m}^{*} \mathrm{~kg} * \mathrm{~m} / \mathrm{s}^{2} / \mathrm{m}^{2}\right)$ & $=$ & $m$ \\
\hline For FOS & $=$ & 4 \\
\hline $\mathrm{L}$ & $=$ & 4.91 \\
\hline PLUG LENGTH FOR STATIC LOADING & $\longrightarrow$ & $5 \mathrm{~m}$ \\
\hline
\end{tabular}




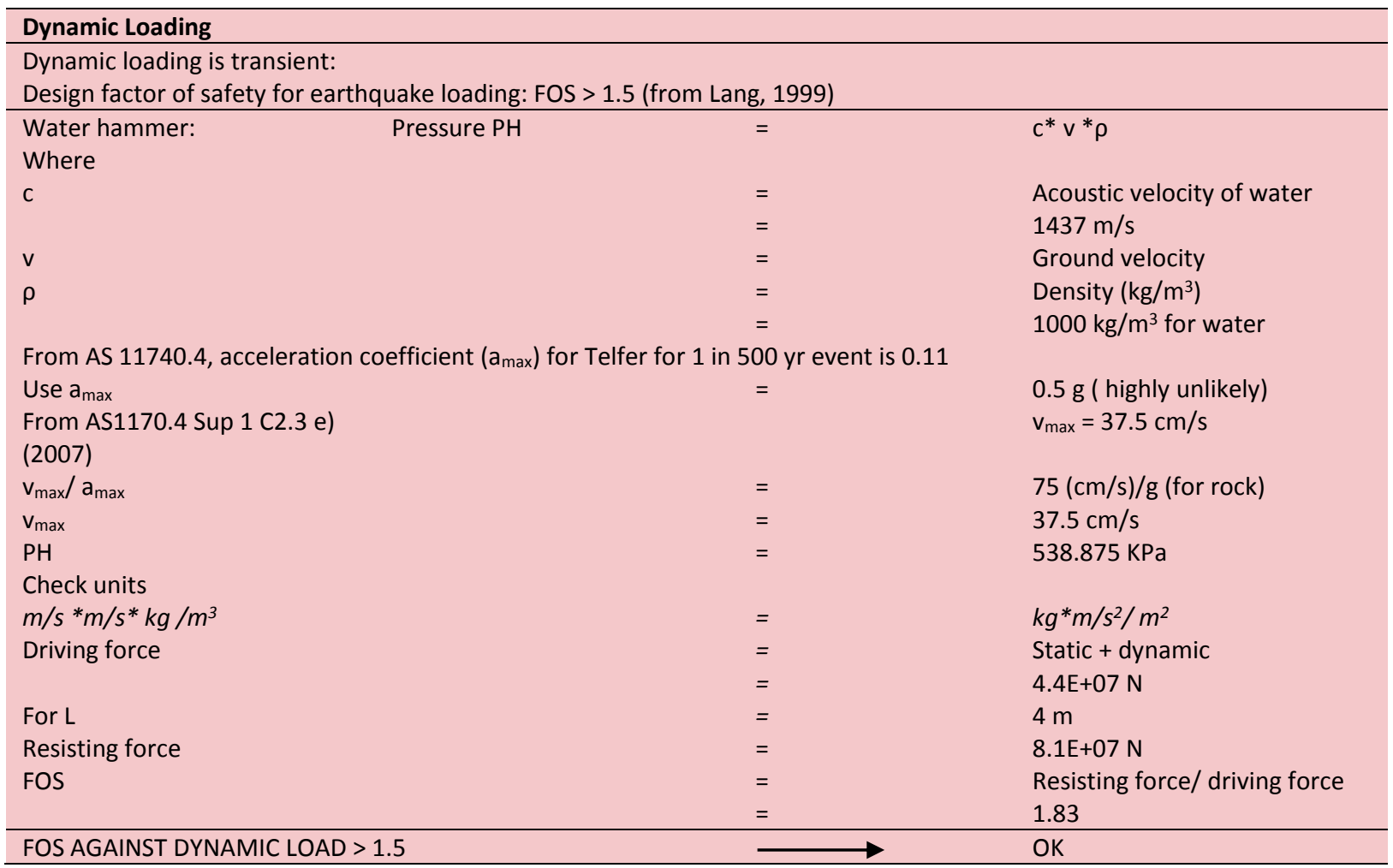

\section{Deep Beam Bending}

To avoid beam bending, require plug length to be greater than maximum dimension
Length $>$ width
$5 m>6 m$
Length $>$ height
$5 m>6 m$

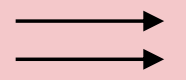
NG (no good)
South African practice requires length $>$ diagonal

Diagonal

Diagonal

Diagonal $>5 \mathrm{~m}$

$=\quad \operatorname{sqrt}\left(w^{2}+h^{2}\right)$

Given lower head for this plug, it is recommended to use the lower threshold

$8.49 \mathrm{~m}$

Design plug length to be greater than maximum dimension

NEW PLUG LENGTH

$+$

$6 \mathrm{~m}$

\begin{tabular}{|c|c|c|c|c|}
\hline Hydrauli & & & & \\
\hline Minimum & cipal stress shc & $\mathrm{rau}$ & & \\
\hline Minimun & & & & \\
\hline$\sigma_{v}$ & & $=$ & Weight of rock due to depth & cover \\
\hline For slopir & 3 Pit) & & & \\
\hline CRM & & $=$ & $\mathrm{Hs} * \rho_{\mathrm{w}} * \mathrm{~F} /\left(\rho_{\mathrm{R}} \operatorname{Cos} \beta\right)$ & (Lang, 1999) \\
\hline Where & & & & \\
\hline & $\rho_{\mathrm{w}}$ & $=$ & Density of water & \\
\hline & & $=$ & $1000 \mathrm{~kg} / \mathrm{m}^{3}$ & \\
\hline & $\rho_{R}$ & $=$ & Density of rock & \\
\hline & & $=$ & $2700 \mathrm{~kg} / \mathrm{m}^{3}$ & \\
\hline & $\mathrm{F}$ & $=$ & Factor of safety & \\
\hline & $\mathrm{Hs}$ & $=$ & Static design head of water & \\
\hline & $\beta$ & $=$ & Slope angle of topography & \\
\hline & & $=$ & $40 \mathrm{deg}$ & \\
\hline & CRM & $=$ & Minimum rock cover from $\mathrm{n}$ & est point \\
\hline For FOS & $\mathrm{F}$ & $=$ & 1.3 (recommended by Lang, & \\
\hline CRM & & $=$ & 43.997 & \\
\hline Minimum & & - & $\rightarrow$ & $50 \mathrm{~m}$ \\
\hline Stage $3 c$ & hich is $>50 \mathrm{~m}$ & & $\rightarrow$ & OK \\
\hline
\end{tabular}




\begin{tabular}{|c|c|c|c|}
\hline \multicolumn{4}{|l|}{ Allowable Hydraulic Gradient } \\
\hline \multicolumn{4}{|l|}{ Note: } \\
\hline \multicolumn{4}{|c|}{ For South African designers, seepage through rock of $0.25-1 \mathrm{l} / \mathrm{sec}$ is OK (Garrett and Campbell Pitt, 1961) } \\
\hline \multirow[t]{2}{*}{ Hydraulic gradient } & $=$ & \multicolumn{2}{|c|}{ Design head of water/ length of plug } \\
\hline & $=$ & \multicolumn{2}{|c|}{$\mathrm{Hw} / \mathrm{L}$} \\
\hline \multirow{3}{*}{$\begin{array}{l}\text { For ungrouted plug allowable gradient } \\
\text { Hydraulic gradient }\end{array}$} & $=$ & \multicolumn{2}{|c|}{14 (Table 1, Good rock) } \\
\hline & $=$ & \multicolumn{2}{|c|}{11.67} \\
\hline & $<$ & & OK \\
\hline & & \multicolumn{2}{|c|}{ Grouting is not a design requirement } \\
\hline
\end{tabular}

\begin{tabular}{|c|c|c|}
\hline \multicolumn{3}{|l|}{ Grouting to be Conducted as a Precaution } \\
\hline \multicolumn{3}{|l|}{ Target grouting pressure, from HSE (UK HSE, 2005): } \\
\hline \multirow[t]{2}{*}{ Grouting pressure } & $>$ & $1.25 *$ hydraulic pressure \\
\hline & $>$ & $1.25^{*} \rho_{w}{ }^{*} g^{*} \mathrm{Hw}$ \\
\hline \multirow[t]{2}{*}{ Grouting pressure } & $<$ & $0.8 *$ geostatic pressure \\
\hline & $<$ & $0.8^{*} \rho_{R}{ }^{*} g^{*} H R$ \\
\hline $\mathrm{H}_{\text {rock }}$ & $>$ & $85 \mathrm{~m}$ from Stage 3 pit design \\
\hline Grouting pressure & $>$ & $686.7 \mathrm{KPa}$ \\
\hline Grouting pressure & $<$ & $1801.1 \mathrm{KPa}$ \\
\hline \multicolumn{3}{|l|}{ Check units } \\
\hline \multirow[t]{2}{*}{$m^{*} \mathrm{~m} / \mathrm{s}^{2 *} \mathrm{~kg} / \mathrm{m}^{3}$} & $=$ & $k g^{*} \mathrm{~m} / \mathrm{s}^{2} / \mathrm{m}^{2}$ \\
\hline & $>$ & $0.7 \mathrm{MPa}$ \\
\hline Target grout pressure & $<$ & $1.8 \mathrm{MPa}$ \\
\hline
\end{tabular}

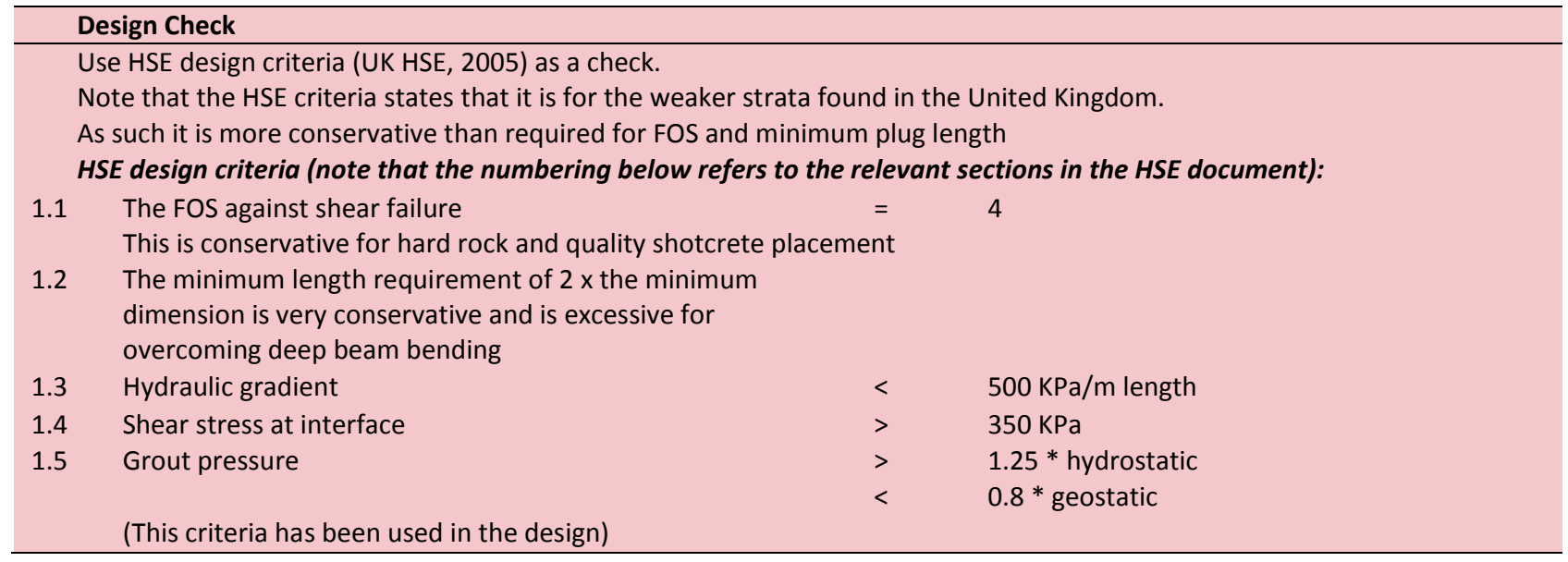

\begin{tabular}{|c|c|c|c|c|}
\hline \multicolumn{5}{|c|}{ Design Check } \\
\hline & Design length & $=$ & $6 \mathrm{~m}$ & \\
\hline \multirow{2}{*}{\multicolumn{2}{|c|}{ Hydrostatic pressure }} & $=$ & $H w^{*} \rho * g$ & \\
\hline & & $=$ & $686.7 \mathrm{KPa}$ & \\
\hline \multirow{2}{*}{\multicolumn{2}{|c|}{ End force }} & $=$ & Hydrostatic pressure ${ }^{*}$ area & \\
\hline & & $=$ & $24721.2 \mathrm{KN}$ & \\
\hline \multirow{2}{*}{\multicolumn{2}{|c|}{ Interface shear area }} & $=$ & Perimeter * length & \\
\hline & & $=$ & $144 \mathrm{~m}^{2}$ & \\
\hline \multirow[t]{4}{*}{1.4} & Interface shear stress & $=$ & End force/ interface shear & \\
\hline & & $=$ & area & \\
\hline & & $<$ & $172 \mathrm{KPa}$ & \\
\hline & & & $350 \mathrm{KPa} \longrightarrow$ & OK \\
\hline \multirow[t]{4}{*}{1.3} & Hydraulic gradient & $=$ & Hydrostatic pressure/plug & \\
\hline & & $=$ & Length & \\
\hline & & $<$ & $114 \mathrm{KPa} / \mathrm{m}$ & \\
\hline & & & $500 \mathrm{KPa} / \mathrm{m}^{-}$ & OK \\
\hline
\end{tabular}

